\title{
Anisi stellati fructus extract attenuates the in vitro and in vivo metastatic and angiogenic potential of malignant cancer cells by downregulating proteolytic activity and pro-angiogenic factors
}

\author{
AEYUNG KIM, MINJU IM and JIN YEUL MA
}

\begin{abstract}
Korean Medicine (KM)-Based Herbal Drug Development Center, Korea Institute of Oriental Medicine (KIOM), Daejeon 305-811, Republic of Korea
\end{abstract}

Received May 7, 2014; Accepted July 2, 2014

DOI: $10.3892 / \mathrm{ijo} .2014 .2606$

\begin{abstract}
Anisi stellati fructus (ASF), commonly known as star anise, has long been used as a traditional Chinese medicine to treat inflammation, nervousness, insomnia and pain. In recent studies, it has been demonstrated that ASF possesses anti-bacterial, anti-fungal and anti-oxidant activities, as well as exhibits inhibitory effects on capillary-like tube formation in human umbilical vein endothelial cells (HUVECs). However, the effects of ASF extract on the metastatic potential of malignant tumor cells have not been examined. In this study, we found that daily oral administration of ASF $(50 \mathrm{mg} / \mathrm{kg}$ ) remarkably reduced the number of pulmonary metastatic colonies of B16F10 cells in C57BL/6J mice with no observed systemic toxicity. In an in vitro system, ASF inhibited metastatic properties, including anchorage-independent colony formation, migration and invasion. Upon phorbol 12-myristate 13-acetate (PMA) stimulation, the mRNA levels of matrix metalloproteinases (MMPs) -9, -13, -14 and urokinase plasminogen activator (uPA) decreased in a dose-dependent manner with ASF treatment. Gelatinase, type I collagenase, and uPA activities were also suppressed efficiently by ASF treatment. In response to PMA, NF- $\kappa \mathrm{B}$ and AP-1 activation as well as p38 phosphorylation, which are crucial for MMP activation, were significantly decreased by ASF. In particular, ASF considerably inhibited tumor-induced HUVEC migration and tube formation and suppressed in vivo tumor-induced angiogenesis via a reduction of pro-angiogenic factors in tumors. These results collectively indicate that ASF might be useful in the management of metastatic malignant tumors.
\end{abstract}

Correspondence to: Dr Jin Yeul Ma, Korean Medicine (KM)-Based Herbal Drug Development Center, Korea Institute of Oriental Medicine (KIOM), 483 Expo-ro, Yuseong-gu, Daejeon 305-811, Republic of Korea

E-mail: jyma@kiom.re.kr

Key words: metastasis, angiogenesis, matrix metalloproteinases, cancer

\section{Introduction}

Metastasis, a highly coordinated step-wise process that includes detachment from the primary tumor, local proteolytic degradation of extracellular matrices (ECMs), extravasation leading to invasion into the new tissue, and formation of metastatic foci, is a hallmark of malignant tumors and major cause of death in cancer patients (1-3). Degradation of ECMs and surrounding basement membranes is promoted by the action of proteinases, such as matrix metalloproteinases (MMPs), plasminogen activators (PAs), serine proteinases and cathepsins $(4,5)$. MMPs, particularly MMP-2 and MMP-9, are elevated in malignant cancer cells and are closely related to poor prognosis and relapse in cancer patients. In addition, MMP-9 is critical for tumor angiogenesis, because it enhances the availability of vascular endothelial cell growth factor (VEGF) in malignant tumors $(6,7)$.

Angiogenesis, the formation of new blood vessels within the primary tumor or metastatic foci, supplies oxygen, nutrients and growth factors for tumor growth, as well as provides a path for cancer cell migration and infiltration (8). Thus, tumors with abundant vasculature exhibit enhanced metastatic potential. During angiogenesis, secretion of angiogenic factors from cancer cells, such as VEGF, basic fibroblast growth factor (bFGF), and platelet-derived growth factor (PDGF), is one of the initial events (9-11). Therefore, inhibition of metastasis and angiogenesis via suppression of MMP activity and angiogenic factor secretion is currently considered a promising strategy in cancer management.

Anisi stellati fructus (ASF), commonly known as star anise (Illicium verum Hook. f), is an important traditional Chinese medicine used in the treatment of vomiting, stomach ache, inflammation, insomnia and rheumatic pain (12). In addition, ASF essential oil is used as a flavoring in confectionery, tobacco and liquor. In addition, ASF is the major source of the chemical compound shikimic acid, a primary ingredient in the pharmaceutical synthesis of anti-influenza drug Tamiflu (13). In recent studies, it has been demonstrated that ASF crude extracts, as well as its active compounds, exhibit a wide range of pharmacological actions, including anti-microbial, anti-fungal, anti-oxidant, insecticidal, analgesic and sedative activity (12). In gas chromatography (GC) and gas chromato-graphy-mass 
spectrometry (GC-MS) analyses, trans-anethole was determined to be a major component in ASF, which possesses muscle relaxant, anti-fungal and anti-cholinesterase activities $(14,15)$. Methanol extracts from fruits and the stem of I. verum moderately inhibited tube-like formation in HUVECs with approximately $50 \%$ inhibition at $10 \mu \mathrm{g} / \mathrm{ml}$, suggesting its anti-angiogenic and anti-cancer activities (16).

In the present study, we examined the effect of ASF on the metastatic and angiogenic potentials of malignant cancer cells in an in vitro and in vivo system. In addition, we elucidate the detailed underlying mechanism. Finally, we also investigated whether oral administration of ASF inhibits pulmonary metastasis of murine melanoma B16F10 cells.

\section{Materials and methods}

Cells and mice. Human fibrosarcoma HT1080 cells (KCLB no. 10121) and human prostate adenocarcinoma PC-3 cells (KCLB no. 21435) were purchased in 2012 from Korean Cell Line Bank (Seoul, Korea), where they were characterized by DNA fingerprinting. Cells were cultured in RPMI-1640 (Lonza, Walkersville, MD, USA) supplemented with $10 \%$ (v/v) heat-inactivated fetal bovine serum (FBS; Gibco/Invitrogen, Carlsbad, CA, USA) and $100 \mathrm{U} / \mathrm{ml}$ penicillin $/ 100 \mu \mathrm{g} / \mathrm{ml} \mathrm{strep-}$ tomycin (Gibco/Invitrogen) at $37^{\circ} \mathrm{C}$ in a humidified $5 \% \mathrm{CO}_{2}$ incubator and routinely screened for mycoplasma contamination. Human umbilical vein endothelial cells (HUVECs) purchased from Innopharmascreen (Asan, Korea) in October, 2012 were maintained in Endothelial Growth Medium-2 (EGM-2; PromoCell, Heidelberg, Germany) and used at passages 3 to 8 in the experiments. Murine melanoma B16F10 cells (KCLB no. 80008), which are metastatic to the lungs of C57BL/6J mice, were obtained in 2012 from Korean Cell Line Bank and cultured in complete Dulbecco's modified Eagle's medium (DMEM; Lonza). Specific pathogen-free female C57BL/6J mice and athymic nude mice were purchased from Taconic Farms Inc. (Samtako Bio Korea, Osan, Korea) and Nara Biotech (Seoul, Korea), respectively, and maintained in our animal facility for 1 week before use. Mice were housed in a barrier facility with 12 -h light-dark cycles at $24 \pm 1^{\circ} \mathrm{C}$ and $55 \pm 5 \%$ humidity under specific pathogen-free conditions. All animal experimental procedures were approved by Korea Institute of Oriental Medicine Care and Use Committee with a reference number of \#13-67 and \#13-94, and performed according to the guidelines established by the Korea Institute of Oriental Medicine Care and Use Committee.

Reagents and antibodies. Type A gelatin from porcine skin, casein from bovine milk, type I collagen from calf skin, 3-(4,5-dimethyl-2-thiazolyl)-2,5-diphenyltetrazolium bromide (MTT), phorbol 12-myristate 13-acetate (PMA), mitomycin C, and curcumin were purchased from Sigma Chemical Co. (St. Louis, MO, USA). Growth factor-reduced Matrigel Basement Membrane Matrix was obtained from BD Biosciences (Bedford, MA, USA), and recombinant mouse basic fibroblast growth factor (rMu bFGF) and recombinant murine vascular endothelial growth factor $165\left(\mathrm{rMu} \mathrm{VEGF}_{165}\right)$ were purchased from PromoKine (Heidelberg, Germany). SB203580, PD98059 and SP600125 were obtained from Calbiochem (San Diego, CA, USA). Antibodies against IкB $\alpha$,
pIкB $\alpha, c-j u n, p-c-j u n, c-f o s, p-c-f o s, N F-\kappa B ~ p 65, p 38, p-p 38$, ERK, p-ERK, JNK, p-JNK and tubulin were obtained from Cell Signaling Technology (Danvers, MA, USA).

Preparation of water extract from ASF. Dried ASF was purchased from Korea Medicine Herbs Association (Yeongcheon, Korea) and deposited in the herbal bank of Korea Institute of Oriental Medicine (KIOM; Daejeon, Korea) after verifying by Professor Ki Hwan Bae of the College of Pharmacy, Chungnam National University (Daejeon, Korea). To prepare aqueous extract of ASF, dried ASF (50 g) were placed in 1 liter of distilled water, and then heat-extracted at $115^{\circ} \mathrm{C}$ for $3 \mathrm{~h}$ in a Cosmos-600 Extractor (Gyeonseo Co., Inchon, Korea). Aqueous extract of ASF was filtered using standard testing sieves (150 $\mu \mathrm{m}$, Retsch, Haan, Germany), and then concentrated by lyophilization. Freeze-dried ASF powder $\left(50 \mathrm{mg}\right.$ ) dissolved in $1 \mathrm{ml}$ of DW was kept at $-20^{\circ} \mathrm{C}$ prior to use after filtration through a $0.22-\mu \mathrm{m}$ disk filter.

Safety assessment after oral administration of ASF. Five-week-old female C57BL/6J mice ( $\mathrm{n}=3$ per group) were daily administered vehicle (saline) or $50 \mathrm{mg} / \mathrm{kg}$ ASF. During 15-day experimental period, gross appearance and behavior were carefully monitored and body weight was daily measured. After sacrifice, organs including heart, liver, lung, spleen and kidneys were weighed. Hematological and serological parameters were measured using ADVIA 2120i hematology system (Siemens Healthcare Diagnostics, Tarrytown, NY, USA) and XL 200 (Erba Diagnostics, Mannheim, Germany), respectively.

Cell viability assay. To examine cytotoxicity of ASF, cells $\left(5 \times 10^{3}\right.$ cells/well/96-well plate) were treated with various concentrations of ASF (10 to $1,000 \mu \mathrm{g} / \mathrm{ml}$ ) for $48 \mathrm{~h}$, and then MTT assay was performed as described previously (17). Relative cell viability was represented as percentage compared with that of untreated control cells.

Anchorage-independent colony forming activity. After HT1080 cells $\left(5 \times 10^{4}\right)$ were suspended in 2 ml RPMI medium with specified concentrations of ASF, $0.3 \%$ agar and $10 \%$ FBS, they were applied to the bottom agar pre-solidified with $3 \mathrm{ml}$ RPMI medium containing 0.6\% agar and 10\% FBS. During incubation for 2 weeks, colony formation was daily observed under a phase-contrast microscope and photographed.

Wound healing assay. In vitro wound healing assay was performed as described previously (17). In brief, HT1080 cells with $90 \%$ confluence were pre-incubated with mitomycin C $(25 \mu \mathrm{g} / \mathrm{ml})$ for $30 \mathrm{~min}$ and scratched by scraping across the cell monolayer. After washing with PBS to eliminate floating cell debris, cells were permitted to migrate for $36 \mathrm{~h}$ in the presence of ASF and wound healing was observed under a phase-contrast microscope and photographed.

Transwell migration and invasion assays. Using a Transwell chamber with polycarbonate membrane $(10 \mathrm{~mm}$ diameter, $8 \mu \mathrm{m}$ pore size), in vitro migration and invasion assays were performed. Transwell chamber coated with $20 \mu 1$ 1:8 mixture of Matrigel: RPMI as the intervening barrier was used for invasion assay. Cells were pre-incubated with indicated 
concentrations of ASF for $12 \mathrm{~h}$. After filling the lower chamber with $600 \mu 1$ 10\% FBS/RPMI, cells $\left(1 \times 10^{5}\right)$ suspended in $100 \mu 1$ serum-free RPMI were added to upper chamber, and incubated for 12 or $24 \mathrm{~h}$ for migration and invasion, respectively. For migration of HUVECs, experimental conditions are specified in the Figures. After removal of the cells remaining in the upper surface of the chamber, migrated and invaded cells were stained with $0.2 \%$ crystal violet $/ 20 \%$ methanol (w/v) solution.

Zymography. The secretions of MMP-2 and MMP-9 in the culture supernatants were measured by gelatin zymography. In brief, cells pre-incubated with ASF in serum-free medium for $12 \mathrm{~h}$ were stimulated with $5 \mathrm{nM}$ PMA for an additional 24 h. Collected serum-free conditioned medium (CM) were electrophoresed on an $8 \%$ SDS-PAGE containing $0.1 \%$ gelatin and gels were washed with washing buffer $(50 \mathrm{mM}$ Tris- $\mathrm{HCl}$, $\mathrm{pH} 7.5,100 \mathrm{mM} \mathrm{NaCl}, 2.5 \%$ Triton X-100) and incubated in reaction buffer $(50 \mathrm{mM}$ Tris- $\mathrm{HCl}, \mathrm{pH} 7.5,150 \mathrm{mM} \mathrm{NaCl}$, $10 \mathrm{mM} \mathrm{CaCl}, 0.02 \% \mathrm{NaN}_{3}, 1 \mu \mathrm{M} \mathrm{ZnCl}_{2}$ ) at $37^{\circ} \mathrm{C}$. Gels were stained with Coomassie Brilliant Blue R-250 staining solution (Bio-Rad Laboratories, Hercules, CA, USA) and destained with $10 \%$ isopropanol $/ 10 \%$ acetic acid (v/v) solution. The secretion of uPA was examined by casein-plasminogen zymography. Conditioned medium were electrophoresed on a $10 \%$ SDS-PAGE containing casein $(1 \mathrm{mg} / \mathrm{ml})$ and human plasminogen $(15 \mu \mathrm{g} / \mathrm{ml})$, and gels were washed, incubated and stained as described earlier. For the detection of collagenase activity, conditioned medium were electrophoresed on a $10 \%$ SDS-PAGE containing collagen (4 mg/ml). MMP-2, MMP-9 and UPA were detected as clear bands against blue background at the size of 72/64, 92 and 55/52 kDa, respectively.

Reverse transcription and polymerase chain reaction $(R T-P C R)$. Total RNA was isolated using PureHelix ${ }^{\mathrm{TM}}$ RNA extraction solution and $3 \mu \mathrm{g}$ RNA was reverse transcribed to cDNA using HelixCript ${ }^{\mathrm{TM}}$ 1st Strand cDNA Synthesis kit (NanoHelix Co., Daejeon, Korea) according to the manufacturer's instructions. The cDNA aliquots were analyzed by semi-quantitative PCR using specific primers (Table I) and PCR products were electrophoresed on $1 \%$ agarose gels and stained with EcoDye ${ }^{\mathrm{TM}}$ (Solgent Co., Daejeon, Korea). Band intensity was quantitatively analyzed using ImageJ software (National Institute of Health, USA) for each gene.

Western blot analysis. Whole cell lysates were extracted using M-PER Mammalian Protein Extraction Reagent (Thermo Scientific, Rockford, IL, USA), and protein concentrations were determined by Bicinchoninic Acid (BCA) kit (Sigma). After immunoblot analysis, proteins were detected using a PowerOpti-ECL Western blotting detection reagent (Animal Genetics, Inc. Korea) and an ImageQuant LAS $4000 \mathrm{mini}$ (GE Healthcare, Piscataway, NJ, USA), and band intensity was analyzed using ImageJ software.

Matrigel plug assay. For tumor-induced angiogenesis, mixture containing PC-3 cells ( $3 \times 10^{6} / 100 \mu \mathrm{l}$ serum-free medium), heparin $(50 \mathrm{U} / \mathrm{ml})$, and Matrigel $(500 \mu \mathrm{l})$ with or without ASF was subcutaneously injected into the abdomen of athymic nude mice. At days 10-14 after implantation, Matrigel plugs were carefully removed and hemoglobin content of the gel plug was
Table I. Primers used for PCR.

\begin{tabular}{ll} 
Target gene & \multicolumn{1}{c}{ Sequence } \\
\hline hMMP-1 & F: 5'-GCAAGTTGAAAAGCGGAGAAAT-3' \\
& R:5'-AAGATTTCCTCCAGGTCCATC-3' \\
hMMP-2 & F: 5'-CCCCAAAACGGACAAAGAGTT-3' \\
& R:5'-AAAGGCATCATCCACTGTCTC-3' \\
hMMP-3 & F: 5'-CACCAGCATGAACCTTGTTCAG-3' \\
& R:5'-CAGCATCTTTTGGCAAATCTGG-3' \\
hMMP-9 & F: 5'-TCTTCCCTGGAGACTGAGAA-3' \\
& R:5'-GGCAAGTCTTCCGAGTAGTTT-3' \\
hMMP-13 & F: 5'-GGCAAACTTGACGATAACACC-3' \\
& R:5'-GCCCATCAAATGGGTAGAAGT-3' \\
hMT1-MMP & F: 5'-CATGCAGAAGTTTTACGGCTTG-3' \\
& R:5'-ACGGATGTAGGCATAGGCA-3' \\
hTIMP-1 & F: 5'-CACCAGAAGTCAACCAGACCA-3' \\
& R:5'-GGGGATGGATAAACAGGGAAAC-3' \\
& F: 5'-AGGGCAGCACTGTGAAATAGA-3' \\
hTIMP-2 & R:5'-TCTTGGACAAGCAGCTTTAGG-3' \\
& F: 5'-AGGGCAGCACTGTGAAATAGA-3' \\
huPA & R:5'-TCTTGGACAAGCAGCTTTAGG-3' \\
hPAI & F: 5'-GCACAATCCCCCATCCTACG-3' \\
& R:5'-GGCTCTCTCCACCTCTGAAA-3' \\
& F: 5'-CCACCCATGGCAAATTCCATGGCA-3' \\
& R:5'-TCTAGACGGCAGGTCAGGTCCACC-3' \\
&
\end{tabular}

F, forward; R, reverse.

Table II. Means of body weights of mice administered with ASF or saline.

Body weight (g)

\begin{tabular}{lcccc}
\cline { 2 - 5 } Treatment & Day 0 & Day 5 & Day 10 & Day 15 \\
\hline Control & $15.99 \pm 0.30$ & $17.12 \pm 0.20$ & $18.16 \pm 0.48$ & $18.75 \pm 0.94$ \\
$50 \mathrm{mg} / \mathrm{kg}$ & $16.15 \pm 0.29$ & $17.14 \pm 0.13$ & $18.19 \pm 0.09$ & $18.94 \pm 0.26$
\end{tabular}

Data are presented as mean $\pm \mathrm{SD}$. Each group of female C57BL/6J mice $(n=3)$ were orally administered $50 \mathrm{mg} / \mathrm{kg}$ of ASF or the same volume of saline daily and weighed at days $0,5,10$ and 15 .

measured using a Drabkin's reagent kit (Sigma) as described previously (18). The concentration of hemoglobin was calculated based on the set of hemoglobin standard (Sigma).

HUVEC tube formation assay. Using an ECMatrix assay kit (Millipore, Temecula, CA, USA), HUVEC tube formation assay was performed according to the manufacturer's instructions. In brief, $10 \mu \mathrm{l}$ chilled ECMatrix was transferred to each well of a pre-cooled $1 \mu$-Slide Angiogenesis ibiTreat chamber (ibidi GmbH, Germany) and allowed to solidify for at least $1 \mathrm{~h}$ at $37^{\circ} \mathrm{C}$. A mixture of HUVECs $\left(5 \times 10^{3}\right.$ cells $)$, bFGF $(1 \mu \mathrm{g} /$ 
Table III. Organ weights of mice administered with ASF or saline.

\begin{tabular}{lcccccc}
\hline & \multicolumn{7}{c}{ Weight of organs (g) } \\
\cline { 2 - 7 } Treatment & Liver & Heart & Lung & Spleen & Kidney (L) & Kidney (R) \\
\hline Control & $0.96 \pm 0.02$ & $0.10 \pm 0.01$ & $0.16 \pm 0.02$ & $0.08 \pm 0.01$ & $0.13 \pm 0.02$ & $0.13 \pm 0.01$ \\
$50 \mathrm{mg} / \mathrm{kg}$ & $0.91 \pm 0.05$ & $0.10 \pm 0.01$ & $0.16 \pm 0.01$ & $0.07 \pm 0.01$ & $0.12 \pm 0.01$ & $0.12 \pm 0.01$ \\
\hline
\end{tabular}

Data are presented as mean $\pm \mathrm{SD}$. Each group of female C57BL/6J mice $(\mathrm{n}=3)$ were orally administered $50 \mathrm{mg} / \mathrm{kg}$ of ASF or the same volume of saline daily, sacrificed at day 15 and the organs were weighed.

Table IV. Chemical analysis of sera obtained from mice administered with ASF or saline.

\begin{tabular}{lcccc}
\hline Treatment & $\begin{array}{c}\text { GOT } \\
(\mathrm{IU} / \mathrm{l})\end{array}$ & $\begin{array}{c}\text { GPT } \\
(\mathrm{IU} / \mathrm{l})\end{array}$ & $\begin{array}{c}\text { BUN } \\
(\mathrm{mg} / \mathrm{dl})\end{array}$ & $\begin{array}{c}\text { CRE } \\
(\mathrm{mg} / \mathrm{dl})\end{array}$ \\
\hline Control & $44.7 \pm 5.0$ & $24.3 \pm 0.6$ & $15.6 \pm 2.7$ & $0.4 \pm 0.1$ \\
$50 \mathrm{mg} / \mathrm{kg}$ & $38.7 \pm 4.6$ & $20.0 \pm 2.1$ & $15.7 \pm 1.3$ & $0.4 \pm 0.0$ \\
\hline
\end{tabular}

Data are presented as mean $\pm \mathrm{SD}$. Each group of female C57BL/6J mice $(n=3)$ were orally administered $50 \mathrm{mg} / \mathrm{kg}$ of ASF or the same volume of saline daily, sacrificed at day 15 , and the levels of GOT, GPT, LDH, BUN and CRE. GOT, glutamic oxaloacetic transaminase; GPT, glutamic pyruvic transaminase; BUN, blood urea nitrogen; CRE, creatinine were analyzed.

$\mathrm{ml}), \mathrm{VEGF}_{165}(100 \mathrm{ng} / \mathrm{ml})$, and/or ASF in endothelial cell basal medium-2 (EBM-2; PromoCell, Heidelberg, Germany), or HUVECs in ASF-treated CM was seeded onto the surface of polymerized ECMatrix, and incubated for 4 to $24 \mathrm{~h}$ at $37^{\circ} \mathrm{C}$. For the collection of CM, cells were treated with ASF for $24 \mathrm{~h}$ in complete media conditions, washed twice with $0.5 \%$ serum media, and then incubated for another $24 \mathrm{~h}$ in $0.5 \%$ serum media. Cellular network-like structures were examined under phase-contrast inverted light microscopy and photographed. Tube formation was quantified by counting tube number and represented as the average of five fields of view in each well.

ELISA for VEGF- $\alpha, b F G F$ and PDGF. Cells were treated with indicated concentrations of ASF for $48 \mathrm{~h}$. The levels of $\mathrm{VEGF}_{165}$, bFGF and PDGF in culture media were determined with the Human ELISA Development kit (Peprotech, Rocky Hill, NJ, USA) according to the manufacturer's instructions.

In vivo pulmonary metastasis assay. After injection of $\mathrm{B} 16 \mathrm{~F} 10$ cells $\left(3 \times 10^{5}\right.$ cells $\left./ 200 \mu \mathrm{l} \mathrm{PBS}\right)$ via the tail veins, $\mathrm{C} 57 \mathrm{BL} / 6 \mathrm{~J}$ mice were randomly divided into 2 groups ( $\mathrm{n}=4$ for each group). Administration of vehicle (saline) or $50 \mathrm{mg} / \mathrm{kg}$ ASF (day 0), for 17 days, mice received daily oral administration and were then sacrificed. Lungs were fixed in Bouin's solution (Sigma) and black colonies were counted macroscopically.

Statistical analysis. The values are presented as means \pm standard deviation (SD). Statistical significance of the difference between groups was analyzed by Two-way analysis of variance
(ANOVA) and Student's t-test with SigmaPlot 8.0 software. P-value $<0.05$ was considered significantly different.

\section{Results}

ASF significantly suppresses in vivo pulmonary metastasis of B16F10 cells without side effects. To examine the anti-metastatic effect of ASF in vivo, we first examined whether repeated administration of ASF $(50 \mathrm{mg} / \mathrm{kg})$ is non-toxic systemically. Over 15 days, corresponding to the in vivo experimental conditions, ASF intake did not influence the body weight of mice (Table II) or cause abnormal behavior or death. Organ weights were not significantly different between control and ASF-treated mice (Table III). In serological analyses, the aspartate aminotransferase/alanine aminotransferase (AST/ALT) and blood urea nitrogen/creatinine (BUN/CRE) ratios were not significantly affected by ASF intake, indicating that ASF did not cause hepatic or renal damage, respectively (Table IV). In hematological analyses, the number of red blood cells (RBCs) and the hemoglobin ( $\mathrm{Hb}$ ) level, an indicator of $\mathrm{RBC}$ balance and anemia, were not altered by ASF intake. In addition, the number of white blood cells (WBCs) and other hematologic parameters were also similar to those of control mice (Table V). Next, we investigated the inhibitory effect of ASF on in vivo tumor metastasis by comparing the ability of $\mathrm{B} 16 \mathrm{~F} 10$ cells to colonize the lungs of $\mathrm{C} 57 \mathrm{BL} / 6 \mathrm{~J}$ mice after tail vein injection. As shown in Fig. 1, B16F10 cells in control mice metastasized to the lungs and formed a considerable number of

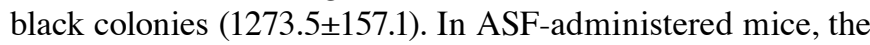
number of black colony in lungs were significantly decreased (402.6 \pm 160.6$)$ to approximately $30 \%$ of control mice. These data indicate that ASF intake effectively inhibited pulmonary metastasis of intravenously injected B16F10 cells with no systemic side effects during treatment.

Non-cytotoxic concentrations of ASF suppress the metastatic potential of HT1080 cells. Prior to evaluation of the in vitro anti-metastatic potential of ASF, we first determined its cytotoxicity in HT1080 cells in the absence or presence of serum using MTT assays. At concentrations up to $250 \mu \mathrm{g} / \mathrm{ml}$, ASF had no cytotoxic effects; however, $500 \mu \mathrm{g} / \mathrm{ml}$ ASF exhibited a $\sim 10 \%$ decrease in cell viability (Fig. 2A). Therefore, we treated cells with 25,50 or $100 \mu \mathrm{g} / \mathrm{ml} \mathrm{ASF}$ in all subsequent experiments. Metastatic cancer cells possess the ability to form colonies in semi-solid agar, which is termed anchorage-independent growth. As shown in Fig. 2B, untreated control HT1080 

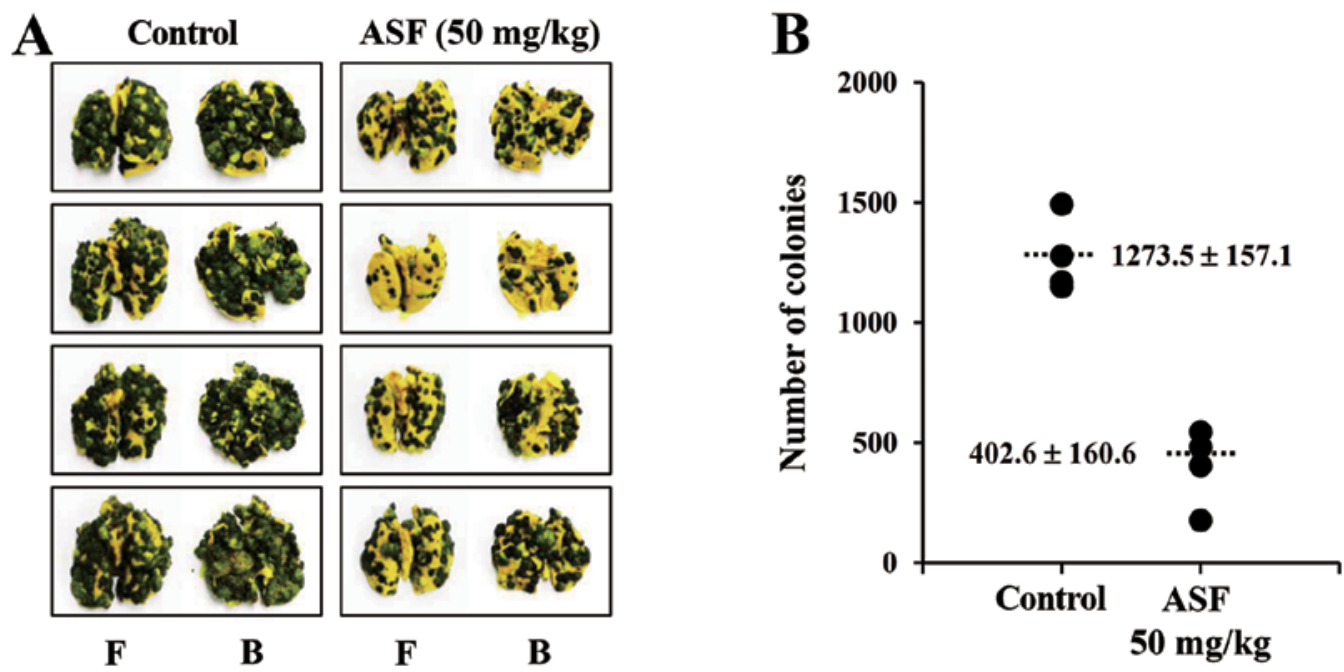

Figure 1. Oral administration of ASF inhibits in vivo pulmonary metastasis of murine melanoma B16F10 cells. (A) After the cells (3x10 ${ }^{5}$ ) were intravenously injected into the tail vein of C57BL/6J mice, ASF $(50 \mathrm{mg} / \mathrm{kg}$ ) was administered daily for 17 days. Mice were sacrificed, and the black colonies settled on the lung surface were fixed and counted macroscopically. Images of metastatic colonies from the front (F) and back (B) of the lungs are shown. (B) Colonies were counted and presented as the mean \pm SD of each group. Data are representative of two independent experiments ( $=4$ per group).

cells formed sizable colonies from a single cell, whereas at concentrations of $25-100 \mu \mathrm{g} / \mathrm{ml}$, ASF remarkably suppressed anchorage-independent growth by approximately 30-63\%. In wound healing assays, control HT1080 cells rapidly migrated across the wound region, leading to approximately 28,50 and $70 \%$ healing at 12,24 and $36 \mathrm{~h}$, respectively. ASF treatments of 25,50 and $100 \mu \mathrm{g} / \mathrm{ml}$ dose-dependently suppressed wound migration to approximately 45,40 and $23 \%$ healing, respectively, at 36 h (Fig. 2C). Using the Transwell culture system, serum-induced migration and invasion were significantly reduced in a dose-dependent manner in ASF-treated HT1080 cells by approximately $20-70$ and $30-90 \%$, respectively, compared with untreated control cells (Fig. 2D).

ASF reduces MMP expression and suppresses proteolytic activity in HT1080 cells. In order to elucidate the anti-metastatic effects of ASF, we first examined the transcriptional levels of various MMPs using semi-quantitative RT-PCR. Under resting conditions, HT1080 cells expressed substantial amounts of MMPs, including MMP-1, -2, -3, -9, -13, MT1-MMP and UPA. PMA stimulation significantly increased MMP-1, -3, -9, -13, MT1-MMP and UPA levels but decreased PAI-1. MMP-2, TIMP-1 and TIMP-2 levels were essentially unchanged by PMA stimulation. However, as shown in Fig. 3A, ASF treatment efficiently inhibited the PMA-induced increase in MMP-9, -13, MT1-MMP and UPA levels and decreased PAI-1 levels dose-dependently. Next, to examine whether ASF influences proteolytic activity of HT1080 cells, we performed zymography using gelatin, collagen type I, and casein-plasminogen as substrates (Fig. 3B). In gelatin zymography, HT1080 cells constitutively secreted MMP-2 and MMP-9. PMA stimulation partially converted proMMP-2 to active MMP-2 and increased MMP-9 activity. ASF treatment dose-dependently suppressed MMP-9 activity in response to PMA stimulation, but it did not prevent PMA-induced conversion to active MMP-2. Collagenase activity in ASF-treated cells
Table V. Hematological analysis of blood obtained from mice administered ASF or saline.

\begin{tabular}{lrr}
\hline Parameter & Control & $50 \mathrm{mg} / \mathrm{kg}$ \\
\hline WBCP $\left(\times 10^{3}\right.$ cells $\left./ \mu \mathrm{l}\right)$ & $2.5 \pm 0.17$ & $2.3 \pm 0.39$ \\
WBCB $\left(\times 10^{3}\right.$ cells $\left./ \mu \mathrm{l}\right)$ & $2.6 \pm 0.25$ & $2.3 \pm 0.29$ \\
RBC $\left(\times 10^{6}\right.$ cells $\left./ \mu \mathrm{l}\right)$ & $9.2 \pm 0.75$ & $9.2 \pm 0.24$ \\
Means HGB $(\mathrm{g} / \mathrm{dl})$ & $13.5 \pm 1.18$ & $13.6 \pm 0.45$ \\
HCT $(\%)$ & $49.1 \pm 4.37$ & $49.4 \pm 1.45$ \\
MCV $(\mathrm{fl})$ & $53.1 \pm 0.92$ & $53.5 \pm 0.31$ \\
MCH $(\mathrm{pg})$ & $14.6 \pm 0.26$ & $14.8 \pm 0.15$ \\
MCHC $(\mathrm{g} / \mathrm{dl})$ & $27.5 \pm 0.10$ & $27.6 \pm 0.23$ \\
PLT $(\mathrm{x} 104$ cells $/ \mu \mathrm{l})$ & $102.5 \pm 11.12$ & $97.8 \pm 1.91$ \\
$\%$ NEUT & $6.5 \pm 1.62$ & $6.4 \pm 1.60$ \\
$\%$ LYM & $87.9 \pm 3.30$ & $86.4 \pm 6.52$ \\
$\%$ MONO & $0.5 \pm 0.01$ & $0.5 \pm 0.15$ \\
\hline
\end{tabular}

Data are presented as mean \pm SD. Each group of mice $(n=3)$ were orally administered $50 \mathrm{mg} / \mathrm{kg}$ of ASF or saline daily, sacrificed at day 15, and hematologic parameters were analyzed. CBC, complete blood cell count; WBCP, white blood cell count peroxidase method; WBCB, white blood cell count basophile method; RBC, red blood cell count; HGB, hemoglobin, HCT, hematocrit; MCV, mean corpuscular volume; MCH, mean corpuscular hemoglobin; MCHC, mean corpuscular hemoglobin concentration; PLT, platelet; NEUT, neutrophil; LYM, lymphocyte; MONO, monocyte.

was also lower compared with control cells. Furthermore, in casein-plasminogen zymography, uPA activity after PMA-stimulation was remarkably reduced by ASF treatment in a dose-dependent manner. These results indicate that ASF suppresses the metastatic potential of HT1080 cells via downregulation of proteolytic activities. In U937 human leukemic monocyte lymphoma cells and PC-3 human 

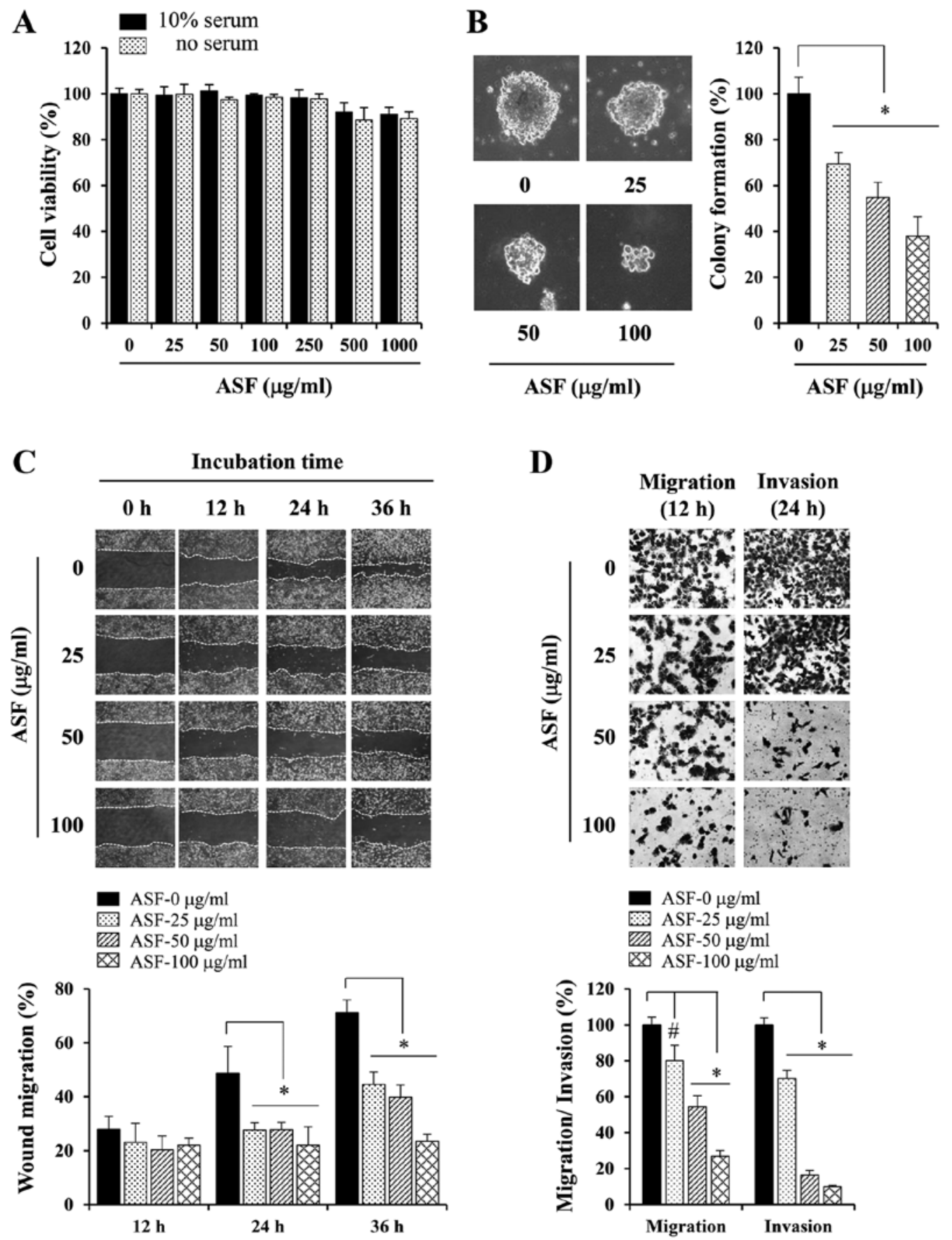

Figure 2. ASF treatment suppresses the metastatic potential of human fibrosarcoma HT1080 cells. (A) Cells (5x103/well) were seeded in 96-well culture plates, treated with 25 to $1,000 \mu \mathrm{g} / \mathrm{ml}$ ASF in the presence or absence of serum for $48 \mathrm{~h}$, and cell viability was determined using MTT assays. (B) Anchorage-independent colony formation in soft agar was measured after incubation for 14 days with non-cytotoxic concentrations of ASF ( 25,50 and $100 \mu \mathrm{g} / \mathrm{ml})$. The diameters of 10 representative colonies were measured and expressed as the mean $\pm \mathrm{SD}$. (C) Confluent cell monolayers were pre-treated with mitomycin C ( $25 \mu \mathrm{g} / \mathrm{ml})$ for $30 \mathrm{~min}$, and injury lines were then created. After washing detached cell debris completely, cells were incubated with ASF for $36 \mathrm{~h}$, and migration was measured using phase-contrast microscopy after 12,24 and $36 \mathrm{~h}$. Based on the width of injury at $0 \mathrm{~h}$, relative wound migration was calculated and expressed as the mean $\pm \mathrm{SD}$ of four selected fields. (D) Cells pre-treated with ASF were monitored for Transwell migration and Matrigel invasion. After incubation, cells that migrated and invaded the lower surface of the Transwell membrane were stained and observed using phase-contrast microscopy. Relative migration and invasion were quantified using ImageJ software, and data are expressed as the means \pm SD of five random fields from each well. ${ }^{*}$ p $<0.01$ vs. untreated control.

prostate cancer cells, ASF significantly decreased MMP-9 gelatinolytic activity (Fig. 3C), further supporting the inhibitory effect of ASF on proteolytic degradation.

ASF suppresses PMA-induced NF- $\kappa B$ and AP-1 activation as well as p38 phosphorylation. It has been reported that the transcription factors NF- $\kappa \mathrm{B}$ and AP-1 are involved in regulating MMP expression and invasion in various cancer cell types (19-21). To examine whether the anti-metastatic effect of ASF is linked to the suppression of NF- $\kappa B$ and AP- 1 activities, we examined the levels of $p-\operatorname{I\kappa B} \alpha, \operatorname{I\kappa B} \alpha$, $\mathrm{p}$-c-jun, and $\mathrm{p}$-c-fos in response to PMA stimulation using 
A
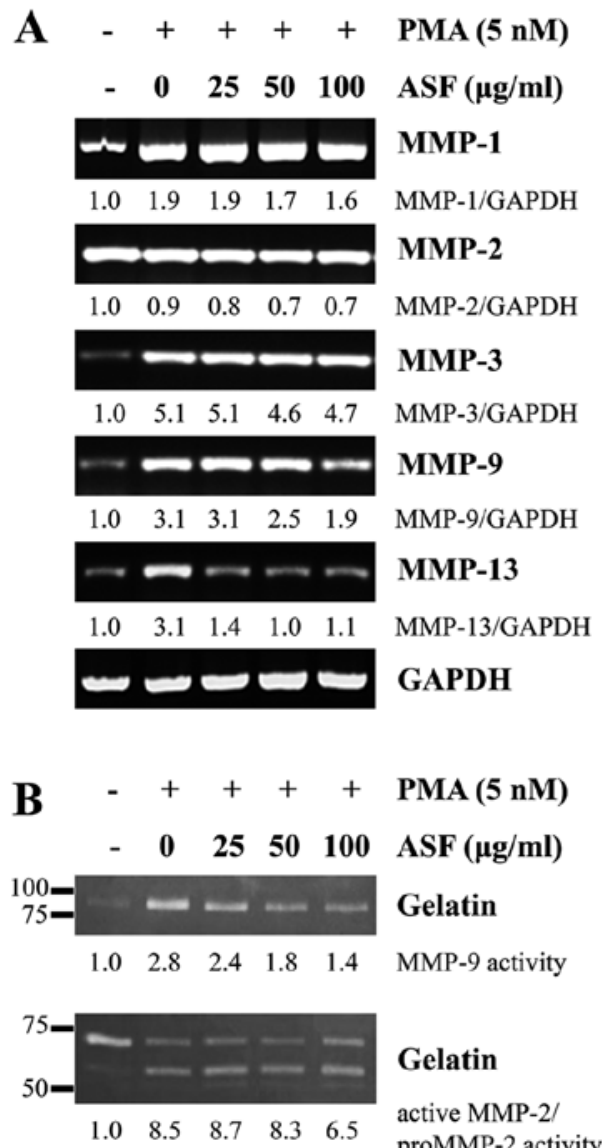

Gelatin

active MMP-2/ proMMP-2 activity

C

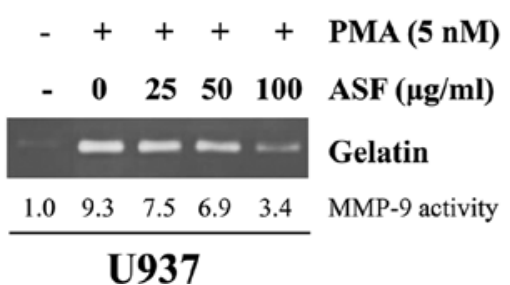

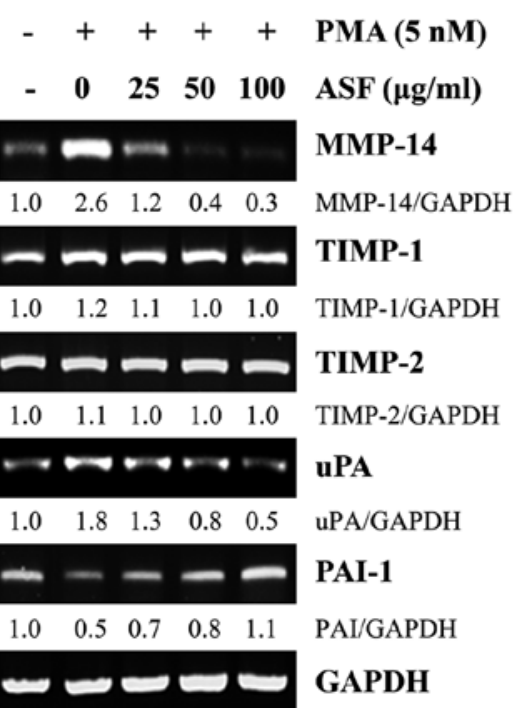
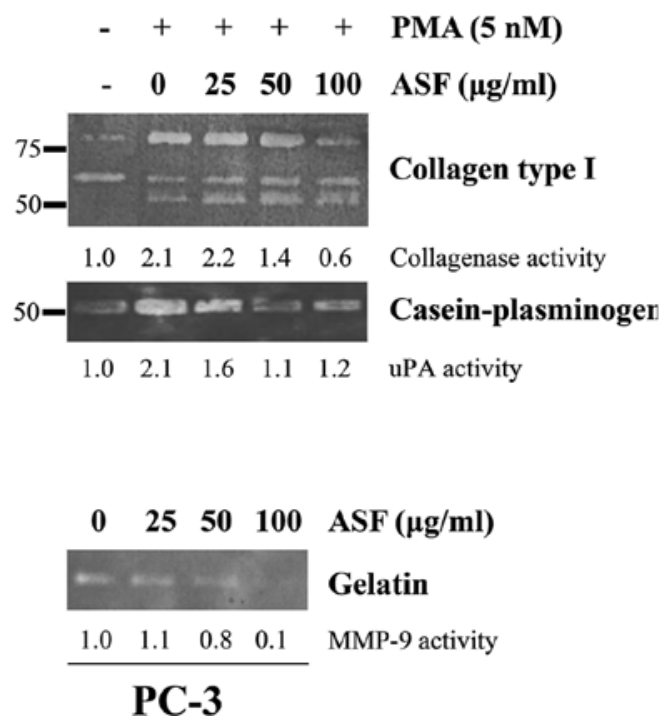

Figure 3. ASF treatment reduces PMA-induced MMP expression and proteolytic activities. (A) Cells were pre-treated for $12 \mathrm{~h}$ with the indicated concentrations of ASF and stimulated with PMA (5 nM) for $24 \mathrm{~h}$ in serum-free media. The mRNA expression of various MMPs was measured using RT-PCR. (B) Each CM was collected and subjected to zymography using gelatin, collagen type I, and casein-plasminogen as substrates. Band intensity was analyzed using Image J software and compared with untreated control cells. Results are representative of two independent experiments. (C) The gelatinolytic activities of U937 and PC-3 cells were also examined using gelatin zymography.

western blot analyses in control cells and ASF-treated cells. As shown in Fig. 4A, I $\kappa \mathrm{B} \alpha$ phosphorylation and degradation were markedly increased by PMA stimulation in control cells. However, in ASF-treated cells, the extent of $\mathrm{I} \kappa \mathrm{B} \alpha$ phosphorylation and degradation was insignificant. Phosphorylation of c-jun and c-fos was also increased by PMA stimulation in control cells, whereas c-fos phosphorylation was almost completely blocked by ASF treatment. In addition, ASF-mediated suppression of phosphorylation of both $\mathrm{I} \kappa \mathrm{B} \alpha$ and c-fos was dose-dependent (Fig. 4B). In control cells, the p65 subunit translocated from the cytosol to the nucleus upon PMA stimulation. In ASF-treated cells, however, p65 nuclear translocation was significantly inhibited in a dose-dependent manner (Fig. 4C). It has been reported that activation of MAPKs, including p38, ERK and JNK, plays a pivotal role in increasing MMP-9 activity and expression (22). As shown in Fig. 4D, phosphorylation of p38, ERK and JNK was rapidly increased by PMA stimulation in control cells. In ASF-treated cells, PMA-induced p38 phosphorylation was almost completely blocked, but ERK and JNK phosphorylation was only partially inhibited. To confirm the involvement of these signal transduction pathways in PMA-stimulated MMP-9 expression and ASF-mediated inhibition, we used gelatin zymography to analyze the effects of specific inhibitors on PMA-induced MMP-9 activity in HT1080 cells. As reported previously, we found that PMA-induced MMP-9 activity was almost completely inhibited by the p38 inhibitor (SB203580) and was significantly inhibited by inhibitors of ERK (PD98059), JNK (SP600125), and AP-1 (curcumin) (22). In addition, PMA-induced MMP-9 activity was significantly reduced by transient expression of dominant negative I $\mathrm{KB}$ kinase, 
$\mathbf{A}$

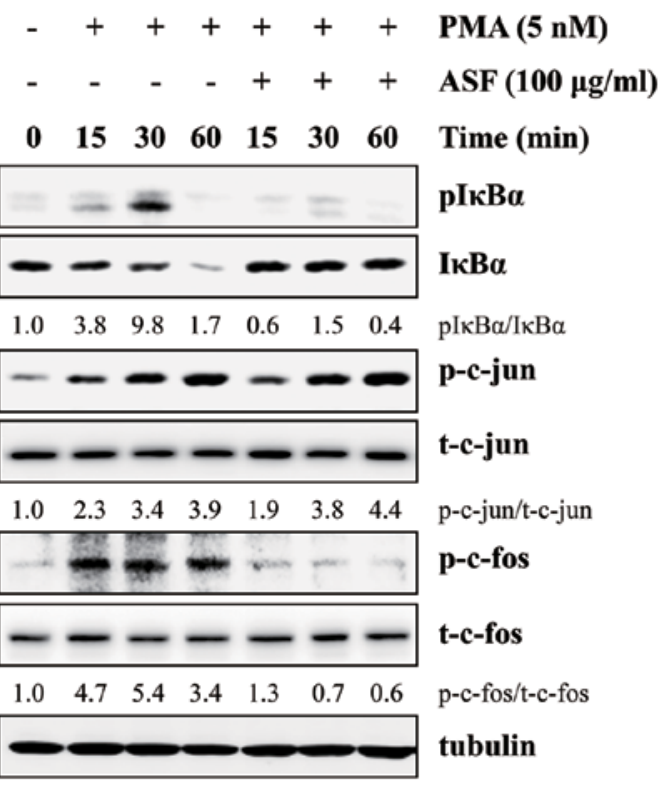

B

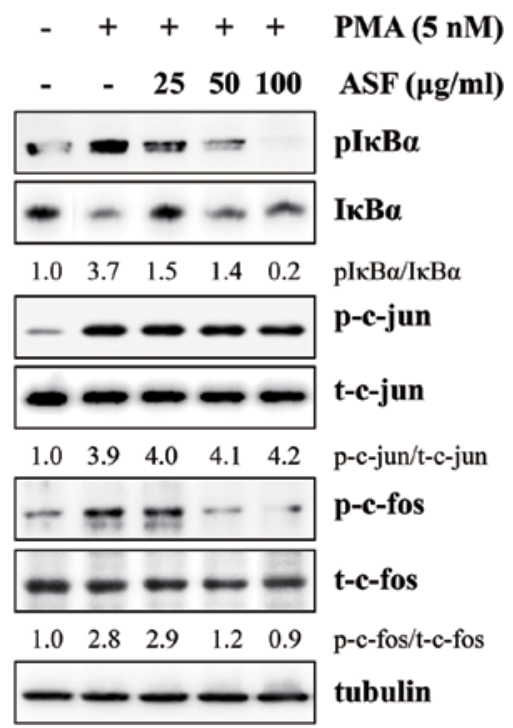

C
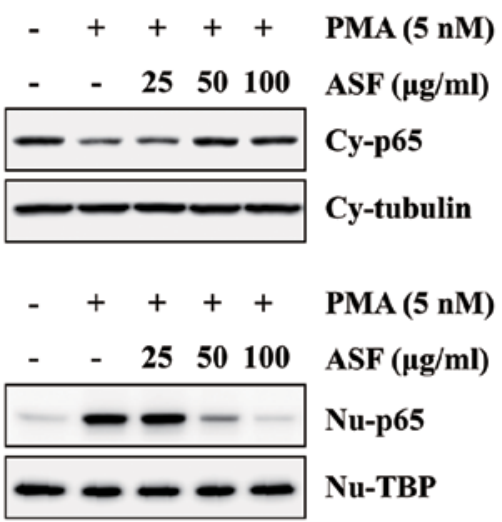

$\begin{array}{llllll}1.0 & 11.2 & 10.6 & 2.8 & 0.9 & \text { Nu-p65/Cy-p65 }\end{array}$
D

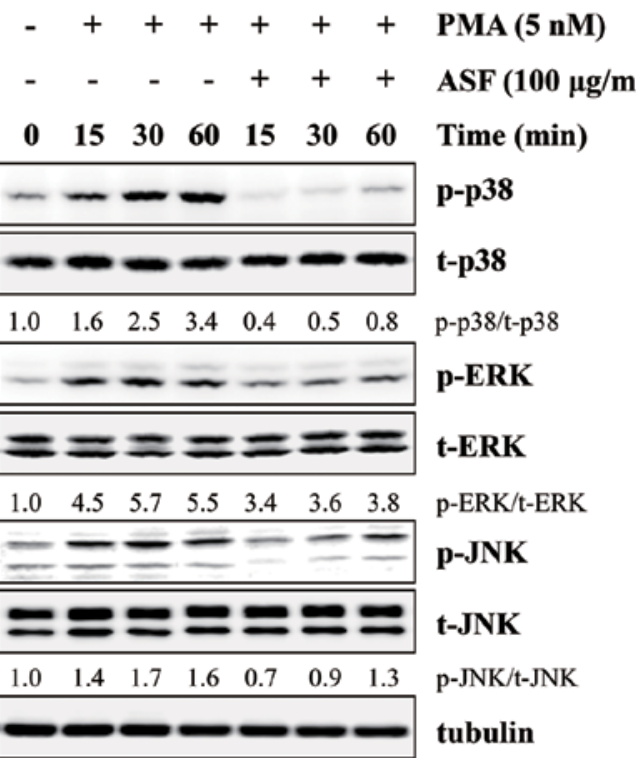

Figure 4. ASF treatment blocks PMA-induced NF- $\kappa$ B and AP-1 activation, as well as p38 phosphorylation. (A) Control and ASF (100 $\mu \mathrm{g} / \mathrm{ml}$ )-treated HT1080 cells $(12 \mathrm{~h})$ were stimulated with $5 \mathrm{nM}$ PMA for 15,30 or $60 \mathrm{~min}$, and cell lysates were evaluated for IкB $\alpha$ phosphorylation and degradation and c-jun/c-fos phosphorylation using western blots. (B) Cells pre-treated with ASF (25, 50 or $100 \mu \mathrm{g} / \mathrm{ml}$ ) for $12 \mathrm{~h}$ were stimulated with PMA for 30 min and then subjected to western blot analysis. (C) To evaluate nuclear translocation of the NF- $\kappa$ B p65 subunit after PMA stimulation, cell lysates were separated into cytosolic and nuclear compartments. (D) Cell lysates prepared as described in panel A were subjected to western blot analysis to evaluate phosphorylation of p38, ERK and JNK. After normalization to tubulin or TBP levels, the relative ratios of $\mathrm{pI \kappa \textrm {B }} \alpha / \mathrm{I} \kappa \mathrm{B} \alpha$, nuclear $\mathrm{p} 65 /$ cytosolic p65, and phosphorylated protein/total protein were calculated. Data were derived from a single analysis, representative of two independent experiments.

dnIKK $\alpha$ or dnIKK $\beta$ (data not shown) (18). These results indicate that specific inhibition of $\mathrm{p} 38, \mathrm{ERK}, \mathrm{JNK}, \mathrm{NF}-\kappa \mathrm{B}$ and AP-1 contributes to suppression of PMA-induced MMP-9 activity.

ASF inhibits in vivo tumor angiogenesis through suppression of pro-angiogenic factors in tumors. Angiogenesis, regulated by angiogenic factors produced by tumor cells, is critical for growth, invasion and metastasis of solid tumors (8). To examine the effect of ASF on tumor-induced angiogenesis in vivo, we performed Matrigel plug assays in athymic nude mice. As reported previously, PC-3 cells remarkably induced formation of new blood vessels in the Matrigel plug, and the plugs exhibited a bright red color (Fig. 5A) (23). In the presence of ASF, Matrigel plugs were light red/yellow in color, indicating inhibition of angiogenesis. The hemoglobin content in the plug with the PC-3 cells was $15.6 \mathrm{mg} / \mathrm{g}$. ASF treatment significantly decreased hemoglobin levels by approximately 50\%, suggesting that ASF can inhibit tumorinduced angiogenesis in vivo. The levels of pro-angiogenic factors, including VEGF- $\alpha$, bFGF and PDGF, in conditioned media (CM) from ASF-untreated and -treated PC-3 cells 

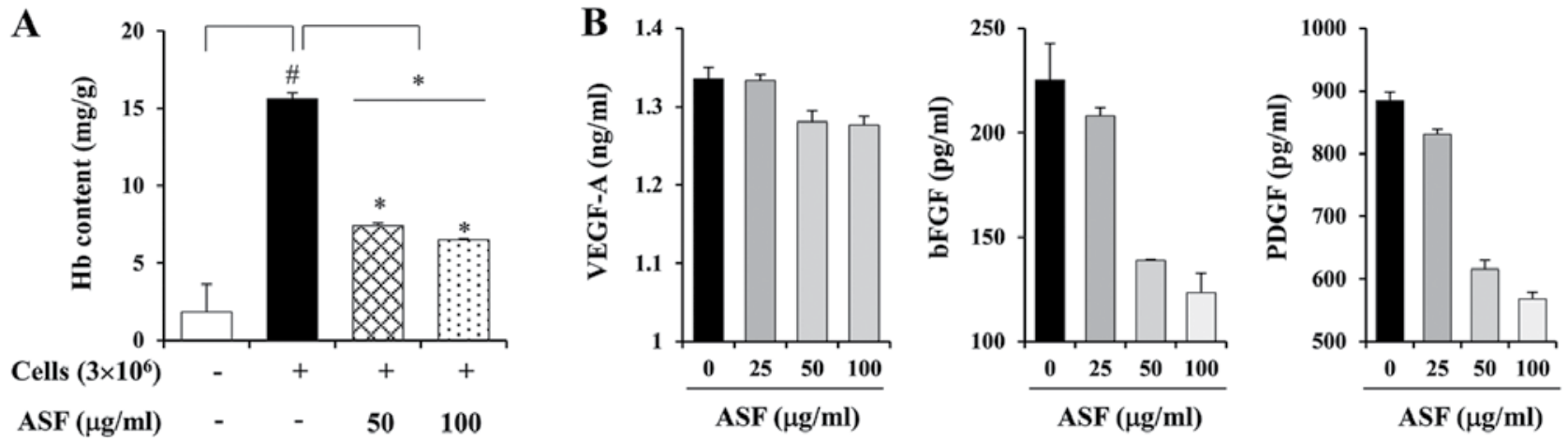

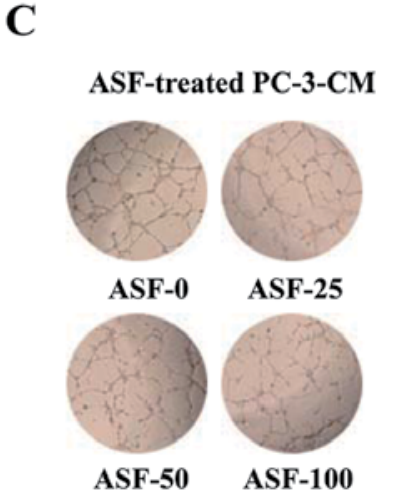

E

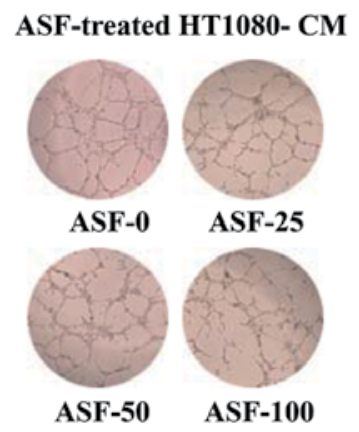

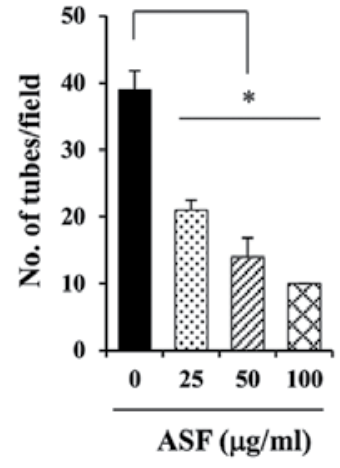

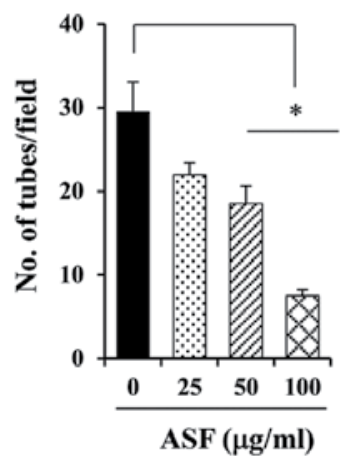

D
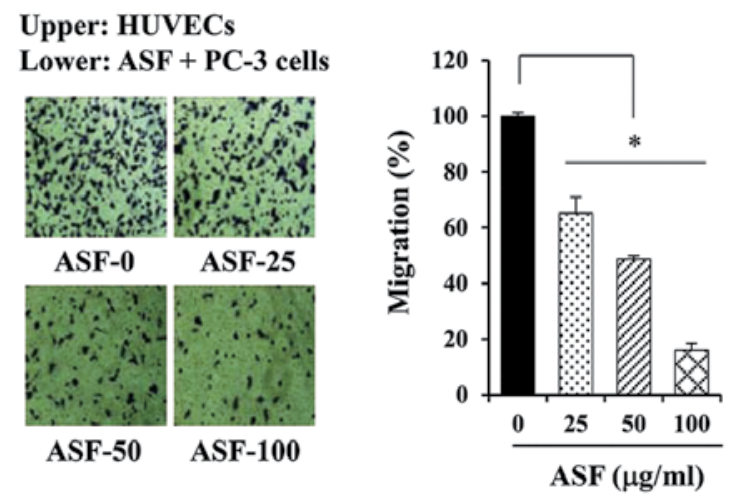

F Upper: HUVECs Lower: ASF + HT1080 cells
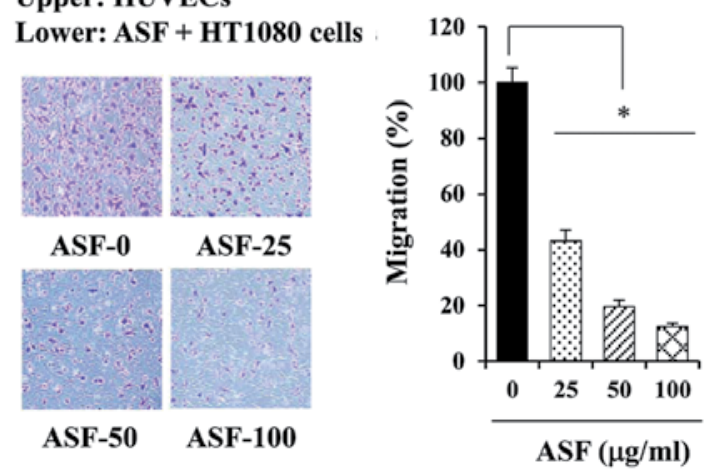

Figure 5. ASF treatment suppresses tumor-induced angiogenesis. (A) Aliquots of PC-3 cells (3x106/100 $\mu 1)$ suspended in serum-free media were mixed with Matrigel in the presence or absence of ASF and subcutaneously implanted into the abdomen of athymic nude mice. After 14 days, Matrigels were carefully removed from the mice, and $\mathrm{Hb}$ levels in plugs were quantified using Drabkin's reagent kit. Data represent the means $\pm \mathrm{SD}$ of each group ( $=3$ ). ${ }^{\#} \mathrm{p}<0.01$ vs. Matrigel alone. " p<0.01 vs. ASF-untreated control cells. (B) PC-3 cells were treated with ASF for $48 \mathrm{~h}$, and the levels of VEGF- $\alpha$, bFGF and PDGF in conditioned media (CM) were determined by ELISA. (C) Capillary-like tube formation of HUVECs induced by control CM or ASF-treated CM of PC-3 cells was examined. The number of tubes was counted in five random fields and expressed as the mean \pm SD. Images are representative of three independent experiments. ${ }^{*} \mathrm{p}<0.01 \mathrm{vs}$. ASF-untreated control CM. (D) In the lower chamber, PC-3 cells pretreated with ASF for $12 \mathrm{~h}$ were plated in $0.5 \%$ serum media. HUVECs suspended in $0.5 \%$ serum media were added to the upper chamber of the Transwell plate and allowed to migrate. After 24 h, HUVECs that migrated to the lower surface were stained, and relative migration was quantified using ImageJ software. " p $<0.01$ vs. ASF-untreated PC-3 cells. (E) Capillary-like tube formation of HUVECs induced by control CM or ASF-treated CM of HT1080 cells was examined as described in (C). ${ }^{*} \mathrm{p}<0.01$ vs. ASF-untreated control CM. (F) Transwell migration of HUVEC induced by ASF-treated HT1080 cells was assessed as described in (D). " p<0.01 vs. ASF-untreated HT1080 cells.

were determined using ELISA analyses. We found that ASF treatment significantly decreased the production of angiogenic factors (Fig. 5B). In addition, we observed that CM from control PC-3 cells strongly induced tube formation in HUVECs. However, in HUVECs plated with CM from ASF-treated PC-3, tube formation was considerably diminished in terms of tubular network and tube number (Fig. 5C). During neovascularization, cancer cells attract endothelial cells by secretion of pro-angiogenic factors. To examine whether ASF could inhibit endothelial cell migration toward PC-3 cells, we used Transwell migration assays and seeded HUVECs in the upper chamber and ASF-treated PC-3 cells in the lower chamber. As shown in Fig. 5D, PC-3 cells in the lower chambers induced migration of HUVECs. ASF treatment of PC-3 cells reduced HUVEC migration toward PC-3 cells in a dose-dependent manner, indicating that ASF 


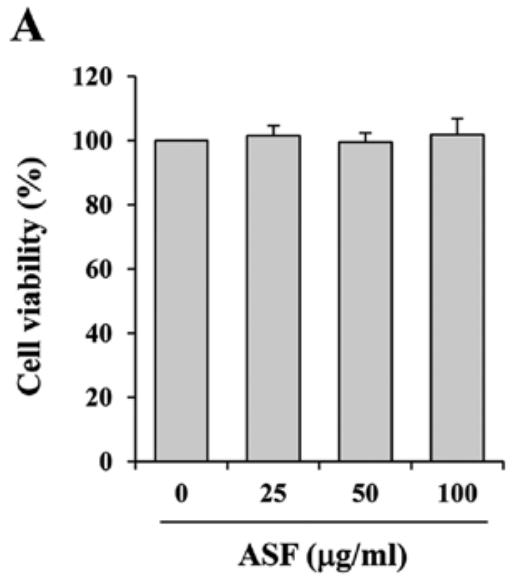

C

\section{Upper: HUVECs + ASF $(\mu \mathrm{g} / \mathrm{ml})$ Bottom: EGM-2}

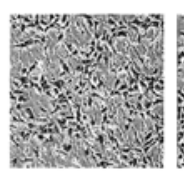

ASF-0

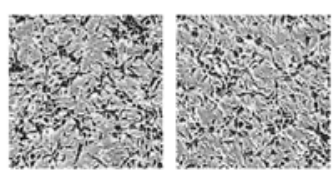

ASF-50 ASF-100

B

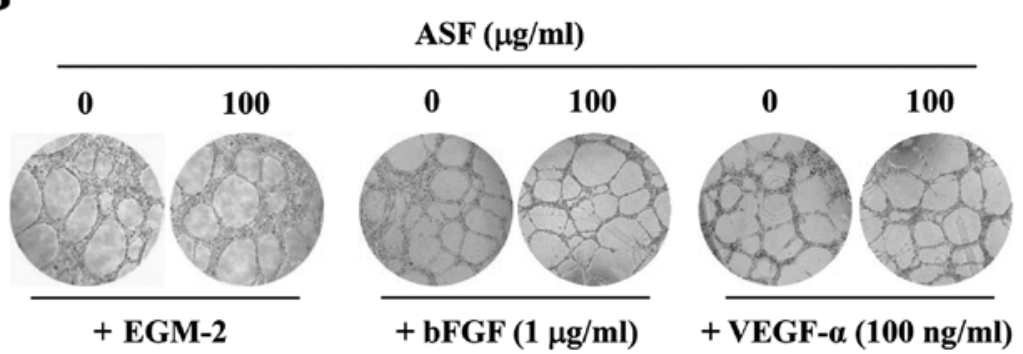

Figure 6. No inhibitory effects of ASF on HUVEC migration and tube formation. (A) HUVECs seeded in 96-well plates were treated for $48 \mathrm{~h}$ with ASF, and cell proliferation was determined using MTT assays. (B) HUVEC capillary-like tube formation induced by EGM-2, bFGF and VEGF- $\alpha$ in the presence of ASF was examined. (C) EGM-2 was added to the lower chamber, and HUVECs in EBM-2 were allowed to migrate in the presence of ASF for $24 \mathrm{~h}$.

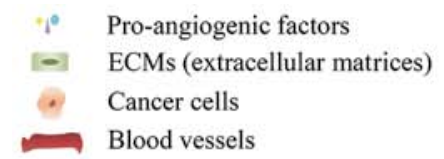

\section{ASF}

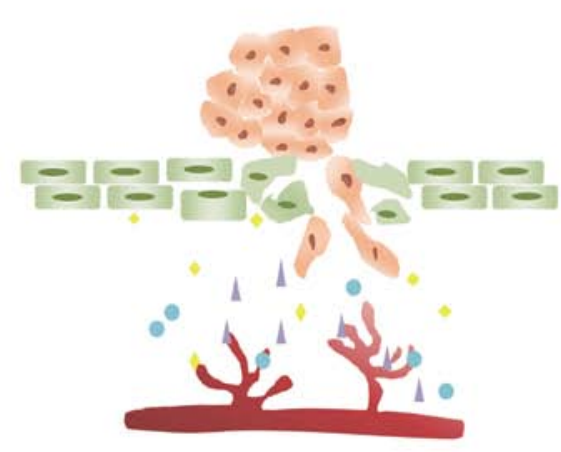

Degradation of ECMs/ MMPs, uPA

Secretion of angiogenic factors

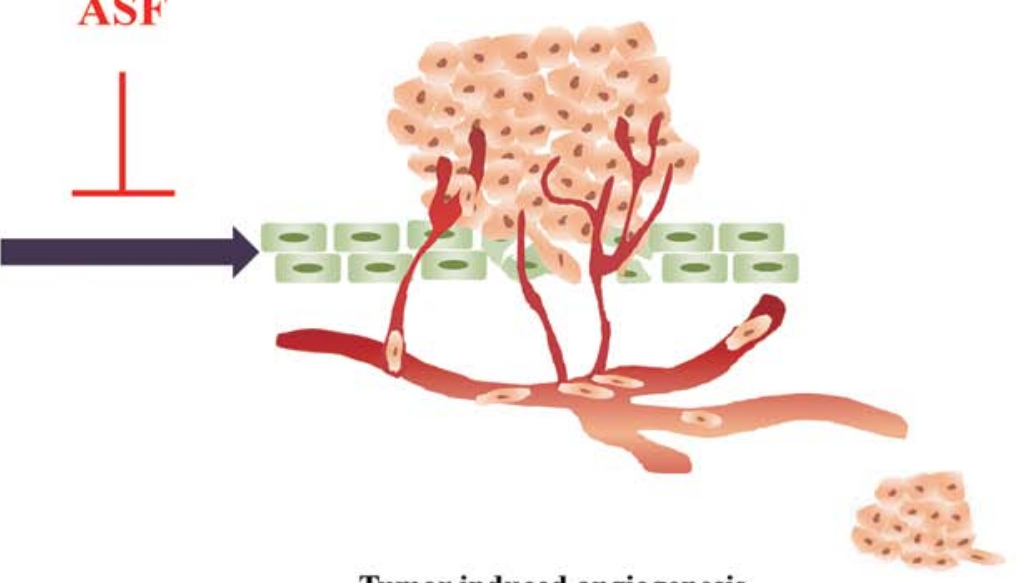

Tumor-induced angiogenesis

Metastasis into new organs

Figure 7. Scheme of the anti-metastatic mechanism of ASF. ASF significantly reduces the metastatic potential of malignant cancer cells by suppression of MMPs activity and tumor-induced angiogenesis.

suppresses tumor cell-derived chemotactic motility of endothelial cells. In ASF-treated HT1080 cells, we also observed strong inhibitory effects on tube formation (Fig. 5E) and HUVEC migration (Fig. 5F). To determine the effects of ASF on endothelial cells, HUVECs in EGM-2 media were treated for $24 \mathrm{~h}$ with 25,50 and $100 \mu \mathrm{g} / \mathrm{ml}$ ASF. Cell viability was analyzed using MTT assays. As shown in Fig. 6A, ASF had no effect on HUVEC proliferation. The degree of EGM-2-, bFGF- and VEGF- $\alpha$-stimulated tube formation in HUVECs was similar between control and ASF-treated HUVECs (Fig. 6B). In addition, EGM-2-mediated migration of HUVECs was not inhibited by ASF treatment (Fig. 6C). 
These data suggest that ASF exerts its anti-angiogenic influence by targeting cancer cells but not endothelial cells.

\section{Discussion}

The anise-scented star-shaped fruit ASF has long been used in traditional Chinese herbal medicine and the food industry in Asian countries. ASF dispels cold and relieves pain, and it is also used in teas to treat nervousness and insomnia (12). ASF contains essential oils, sesquiterpenes, prenylated C6-C3 compounds, lignans and flavonoids. In particular, essential oil from ASF includes trans-anethole (70-94\%), estragole, limonene, pinene, $\beta$-phellandrene and $\alpha$-terpineol (24). To extract the essential oil from ASF, various techniques can be used, including hydrodistillation (HD), steam distillation (SD), solvent extraction (SE), supercritical fluid $\mathrm{CO}_{2}$ extraction (SFE), hydrodistillationheadspace solvent microextraction (HD-HSME) and microwave-assisted extraction (MAE). In addition, it is important to select appropriate solvents for extraction to improve yield and the effect of the medicine. Recent studies have shown that ethanol extract of ASF exerts substantial anti-bacterial activity against 67 drug-resistant isolates (25). Additionally, methanol extract and decoction of ASF also exhibit anti-bacterial activity against Eikenella corrodens (26). Furthermore, ASF has been reported to possess antifungal, anti-oxidant, insecticidal, analgesic, sedative and convulsive activities (14,27-29). In a study by Nam et al, tube-like formation in HUVECs was considerably inhibited by the methanol extract from the fruits and stem of I. verum, suggesting its anticancer activity (16). However, the effects of ASF decoction on tumor growth or the metastatic potential of malignant tumor cells, as well as the underlying mechanism, have not yet been established.

In this study, we demonstrated that water extract of ASF alleviates the metastatic and angiogenic potential of malignant HT1080 cells via suppression of proteolytic activities and reduction of pro-angiogenic factors. In addition, we observed that oral administration of $50 \mathrm{mg} / \mathrm{kg}$ ASF decreases pulmonary metastatic colonies of B16F10 melanoma in vivo with no systemic toxicity, suggesting that ASF can be used as a safe remedy for cancer treatment. In other studies, oral administration of ethyl acetate extract of ASF at a high dose $(500 \mathrm{mg} / \mathrm{kg})$ caused convulsions and lethal toxicity in mice, and veranisatins were identified as the active components $(28,29)$. Veranisatins are also known as analgesic and sedative compounds, indicating that the medicinal and toxic effects depend on the dose.

Highly malignant tumors, which are relatively resistant to current anticancer agents and related to high recurrence and mortality, can efficiently degrade surrounding basement membranes and stromal ECMs via MMP activation (7). The tumors then invade surrounding tissues and enter the bloodstream to metastasize to distant sites. Among MMPs, MMP-9 expression and activity have been closely linked to vascular invasion and aggressiveness $(5,30)$. Our results showed that ASF treatment significantly decreased MMP-9 expression, secretion, and proteolytic activity for gelatin, type I collagen, and casein-plasminogen as substrates, suggesting that ASF can be used to treat malignant metastatic cancers. We also observed that ASF inhibited the production of pro-angiogenic factors in cancer cells, thereby suppressing in vitro tumor-induced migration and tube formation of endothelial cells. Furthermore, using Matrigel plug assays, we found that ASF-treated cancer cells showed lower vascularization in plugs than control cells, supporting the in vivo anti-angiogenic activity of ASF. Because endothelial cells in the tumor microenvironment play a critical role in cancer growth and progression, ASF could be considered to control both cancer cells and endothelial cells.

In response to various agonists, including PMA, MMP-9 activation is induced by MAPKs and the subsequent activation of the transcription factors NF- $\mathrm{kB}$ and AP-1, which are involved in cancer cell adhesion, invasion and angiogenesis $(4,31)$. In this study, ASF almost completed blocked PMA-induced p38 phosphorylation and dramatically decreased PMA-induced NF- $\mathrm{KB}$ and AP-1 activation. As reported in earlier studies, pre-treatment with specific inhibitors significantly decreased PMA-induced MMP-9 activity in our HT1080 cell system (22). These results indicate that blockade of $\mathrm{p} 38, \mathrm{NF}-\mathrm{\kappa B}$ and AP-1 activation by ASF contributes to suppression of the metastatic potential via downregulation of MMP-9 activity.

Anethole, a main ASF phytoconstituent, was reported to possess muscle relaxant and anti-cholinesterase activities (15). In addition, anethole exhibited chemopreventive activities in its suppression of the incidence and multiplicity of both invasive and non-invasive carcinomas (32). Anethole also inhibited cell migration and invasion in human fibrosarcoma cells by inhibiting MMP-2/-9 and Akt/MAPK/NF- $\mathrm{kB}$ signaling pathways (33). These results suggest that anethole derived from ASF may suppress metastasis and angiogenesis in cancer cells.

Collectively, our results demonstrate that ASF exerts anti-metastatic and anti-angiogenic effects on highly malignant cancer cells via downregulation of proteolytic activities and pro-angiogenic factors. Furthermore, we found that repeated oral administration of ASF $(50 \mathrm{mg} / \mathrm{kg})$ significantly reduced the number of metastatic colonies in mice with no adverse effects. These results collectively suggest that ASF may be a safe herbal product used to control metastatic cancer.

\section{Acknowledgements}

This study was supported by the Grant K14050 awarded to Korea Institute of Oriental Medicine (KIOM) from Ministry of Education, Science and Technology (MEST), Republic of Korea.

\section{References}

1. Liotta LA, Steeg PS and Stetler-Stevenson WG: Cancer metastasis and angiogenesis: an imbalance of positive and negative regulation. Cell 64: 327-336, 1991.

2. Patel LR, Camacho DF, Shiozawa Y, Pienta KJ and Taichman RS: Mechanisms of cancer cell metastasis to the bone: a multistep process. Future Oncol 7: 1285-1297, 2011.

3. Deryugina EI and Quigley JP: Matrix metalloproteinases and tumor metastasis. Cancer Metastasis Rev 25: 9-34, 2006.

4. Westermarck J and Kahari VM: Regulation of matrix metalloproteinase expression in tumor invasion. FASEB J 13: 781-792, 1999.

5. Gondi CS, Lakka SS, Dinh DH, Olivero WC, Gujrati M and Rao JS: Downregulation of uPA, uPAR and MMP-9 using small, interfering, hairpin RNA (siRNA) inhibits glioma cell invasion, angiogenesis and tumor growth. Neuron Glia Biol 1: 165-176, 2004. 
6. Lockhart AC, Braun RD, Yu D, et al: Reduction of wound angiogenesis in patients treated with BMS-275291, a broad spectrum matrix metalloproteinase inhibitor. Clin Cancer Res 9: 586-593, 2003

7. Zheng H, Takahashi H, Murai Y, et al: Expressions of MMP-2, MMP-9 and VEGF are closely linked to growth, invasion, metastasis and angiogenesis of gastric carcinoma. Anticancer Res 26: 3579-3583, 2006

8. Folkman J: Role of angiogenesis in tumor growth and metastasis. Semin Oncol 29: 15-18, 2002

9. Bicknell R: Vascular targeting and the inhibition of angiogenesis. Ann Oncol Suppl 4: 45-50, 1994.

10. Appelmann I, Liersch R, Kessler T, Mesters RM and Berdel WE: Angiogenesis inhibition in cancer therapy: platelet-derived growth factor (PDGF) and vascular endothelial growth factor (VEGF) and their receptors: biological functions and role in malignancy. Recent Results Cancer Res 180: 51-81, 2010.

11. Poveshchenko AF and Konenkov VI: Mechanisms and factors of angiogenesis. Usp Fiziol Nauk 41: 68-89, 2010 (In Russian).

12. Wang GW, Hu WT, Huang BK and Qin LP: Illicium verum: a review on its botany, traditional use, chemistry and pharmacology. J Ethnopharmacol 136: 10-20, 2011.

13. Ghosh S, Chisti Y and Banerjee UC: Production of shikimic acid. Biotechnol Adv 30: 1425-1431, 2012.

14. Huang Y, Zhao J, Zhou L, et al: Antifungal activity of the essential oil of Illicium verum fruit and its main component trans-anethole. Molecules 15: 7558-7569, 2010.

15. Bhadra S, Mukherjee PK, Kumar NS and Bandyopadhyay A: Anticholinesterase activity of standardized extract of Illicium verum Hook. f. fruits. Fitoterapia 82: 342-346, 2011.

16. Nam NH, Kim HM, Bae KH and Ahn BZ: Inhibitory effects of Vietnamese medicinal plants on tube-like formation of human umbilical venous cells. Phytother Res 17: 107-111, 2003.

17. Kim A, Im M, Yim NH, Jung YP and Ma JY: Aqueous extract of Bambusae Caulis in Taeniam inhibits PMA-induced tumor cell invasion and pulmonary metastasis: suppression of NF-kappaB activation through ROS signaling. PLoS One 8: e78061, 2013.

18. Kim A, Kim MJ, Yang Y, Kim JW, Yeom YI and Lim JS: Suppression of NF-kappaB activity by NDRG2 expression attenuates the invasive potential of highly malignant tumor cells. Carcinogenesis 30: 927-936, 2009.

19. Cho HJ, Kang JH, Kwak JY, et al: Ascofuranone suppresses PMA-mediated matrix metalloproteinase-9 gene activation through the Ras/Raf/MEK/ERK- and Ap1-dependent mechanisms. Carcinogenesis 28: 1104-1110, 2007.

20. Sato T, Koike L, Miyata Y, et al: Inhibition of activator protein-1 binding activity and phosphatidylinositol 3-kinase pathway by nobiletin, a polymethoxy flavonoid, results in augmentation of tissue inhibitor of metalloproteinases-1 production and suppression of production of matrix metalloproteinases- 1 and -9 in human fibrosarcoma HT-1080 cells. Cancer Res 62: 1025-1029, 2002 .
21. Choi JH, Han EH, Hwang YP, et al: Suppression of PMA-induced tumor cell invasion and metastasis by aqueous extract isolated from Prunella vulgaris via the inhibition of NF-kappaB-dependent MMP-9 expression. Food Chem Toxicol 48: 564-571, 2010

22. Hwang YP, Yun HJ, Kim HG, Han EH, Lee GW and Jeong HG: Suppression of PMA-induced tumor cell invasion by dihydroartemisinin via inhibition of PKCalpha/Raf/MAPKs and NF-kappaB/AP-1-dependent mechanisms. Biochem Pharmacol 79: 1714-1726, 2010

23. Fang J, Zhou Q, Liu LZ, et al: Apigenin inhibits tumor angiogenesis through decreasing HIF-1alpha and VEGF expression. Carcinogenesis 28: 858-864, 2007.

24. Wang Z, Wang L, Li T, et al: Rapid analysis of the essential oils from dried Illicium verum Hook. f. and Zingiber officinale Rosc. by improved solvent-free microwave extraction with three types of microwave-absorption medium. Anal Bioanal Chem 386: 1863-1868, 2006.

25. Yang JF, Yang CH, Chang HW, et al: Chemical composition and antibacterial activities of Illicium verum against antibiotic-resistant pathogens. J Med Food 13: 1254-1262, 2010.

26. Iauk L, Lo Bue AM, Milazzo I, Rapisarda A and Blandino G: Antibacterial activity of medicinal plant extracts against periodontopathic bacteria. Phytother Res 17: 599-604, 2003.

27. Guo DJ, Cheng HL, Chan SW and Yu PH: Antioxidative activities and the total phenolic contents of tonic Chinese medicinal herbs. Inflammopharmacology 16: 201-207, 2008.

28. Nakamura T, Okuyama E and Yamazaki M: Neurotropic components from star anise (Illicium verum Hook. fil.). Chem Pharm Bull 44: 1908-1914, 1996.

29. Okuyama E, Nakamura T and Yamazaki M: Convulsants from star anise (Illicium verum Hook.F.). Chem Pharm Bull 41: 1670-1671, 1993

30. Mira E, Lacalle RA, Buesa JM, et al: Secreted MMP9 promotes angiogenesis more efficiently than constitutive active MMP9 bound to the tumor cell surface. J Cell Sci 117: 1847-1857, 2004.

31. Lee SO, Jeong YJ, Yu MH, et al: Wogonin suppresses TNF-alpha-induced MMP-9 expression by blocking the NF-kappaB activation via MAPK signaling pathways in human aortic smooth muscle cells. Biochem Biophys Res Commun 351: 118-125, 2006.

32. Lubet RA, Steele VE, Eto I, Juliana MM, Kelloff GJ and Grubbs CJ: Chemopreventive efficacy of anethole trithione, $\mathrm{N}$-acetyl-L-cysteine, miconazole and phenethylisothiocyanate in the DMBA-induced rat mammary cancer model. I J Cancer 72: 95-101, 1997.

33. Choo EJ, Rhee YH, Jeong SJ, et al: Anethole exerts antimetatstaic activity via inhibition of matrix metalloproteinase $2 / 9$ and $\mathrm{AKT} / \mathrm{mitogen}$-activated kinase/nuclear factor kappa B signaling pathways. Biol Pharm Bull 34: 41-46, 2011. 